\title{
Sequential Development of Shoot System Components in Eastern Gamagrass
}

\author{
C.L. DEWALD AND V.H. LOUTHAN
}

\begin{abstract}
The sequence of development of shoot system components was studied from early November 1976 through October 1977 in eastern gamagrass. Tiller production and compound shoot development began in late spring and continued until the first killing frost in mid-October. On shoots initiated in 1977, root development began in early August and peaked in September. Single shoots developed one to six mature phytomers during their first growing season. Reproductive shoot development was first noted in early May, peaked in late May, and continued into October. The proaxes of tillers, single shoots, and compound shoots perennated through the 1976-77 winter dormant period. Shoots that over-wintered as tillers had advanced to the single shoot stage by late August 1977 and had produced from 8 to 20 mature phytomers by the end of the growing season. Compound shoots initiated before 1977 developed into reproductive shoots or died by late May 1977. From May through July high percentages of the shoot system components were in the tiller and reproductive shoot stages. During this period vegetative propagation would probably not be feasible and the use of proper management practices might be more critical than during other periods.
\end{abstract}

Eastern gamagrass [Tripsacum dactyloides (L.) L.] has long been recognized as one of the most productive and palatable native grasses of the bottomlands in the southeastern United States. Yields of 168 to 279 metric tons of green grass per hectare were reported by Magoffin (1843). Gamagrass is so palatable that most natural stands have been greatly reduced through preferential grazing by animals (Rechenthin 1951). Hitchcock and Clothier (1899) noted that the hay was nutritious. Characteristics of gamagrass which have hindered its widespread use include inadequate seed production and inferior seed quality, difficulties in vegetative estab!ishment, and lack of persistence under improper grazing (Killebrew 1878; Wilcox and Smith 1905; Polk and Adcock 1964; Ahring and Frank 1968).

The stembase structure of eastern gamagrass has often been referred to as rhizomes (Holm 1929; Hitchcock 1951; Weatherwax 1954; and Wilks 1972). Certain morphological characteristics of this important crown structure of eastern gamagrass, i.e. nonelongated internodes, elaborate true leaves and intravaginal branching habits, do not coincide with definitions of rhizomes given by Strasbuger et al. (1903), Arber (1934), Evans (1958), Sharman (1945) or Youngner (1969). The term "proaxis" has been applied to the stembase of timothy [Phleum pratense L.] (Evans 1927 and 1958) and to blue grama [Bouteloua gracilis (H.B.K.) Lag. ex Stued.] (Stubbendieck and Burzlaff 1971), and refers to the nonelongated internodes that may have fully developed green leaves. Consequently, we consider "proaxis"

Authors are range agronomist and agricultural research technician, U.S. Department of Agriculture, Science and Education Administration, Federal Research, U.S. Southern Great Plains Field Station, Woodward, Oklahoma 73801 to be the appropriate term for the stembase structure of eastern gamagrass.

The proaxis of grasses consists of basal phytomers with very short or nonelongated internodes. A phytomer is a unit of a shoot consisting of a leaf, an internode, an axillary bud or bud potential, and a node (Gray 1879; Evans and Grover 1940; Hyder 1974). Proaxis phytomers contribute to forage production, quality, and perenniality in many grasses. Two to four basal or proaxis phytomer numbers were reported in Indiangrass [Sorghastrum nutans (L.) Nash] and switchgrass [Panicum virgatum L.] and 12 to 15 were found in little bluestem [Schizachyrium scopariu:n (Michx.) Nash] (Rechenthin 1956). Basal phytomer numbers of other grasses have been reported by Evans (1958), Stubbendieck and Burzlaff (1971), and Sims et al. (1973).

Eastern gamagrass is a very complex species, both taxonomically and cytologically (Cutler and Anderson 1941; Anderson 1944). Newell and deWet (1974) showed statistically that this species "consists of highly variable populations encompassing a wide range of morphological entities." It is obvious that tremendous variability exists among populations of eastern gamagrass, and we do not suggest that the results of this study of one genotype will apply to all others.

Despite the potential of eastern gamagrass as an important forage species, little is known about its developmental morphology. Our objective was to determine the sequence of development of shoot system components in eastern gamagrass. Such knowledge may prove useful in (1) formulating the cultural and utilization management practices needed to maximize forage production; (2) determining the reproductivevegetative cycle and the peak and span in reproductive shoot development to help overcome certain seed production limitations; and (3) determining the shift in proportions of vegetative structural components and rooting characteristics so that the most favorable dates for vegetative propagation can be determined. It is essential to know how shoot perenniality, phytomer growth rates, and vegetative expansion through tillering contribute to productivity and stand longevity. Such knowledge is basic to the development of sound management practices.

\section{Materials and Methods}

Plant material used through this study was obtained from an individual crown of eastern gamagrass growing in a windmill exclosure on the Southern Plains Experimental Range near Fort Supply, Oklahoma. The crown was subdivided into propagules that were uniform in size. This plant material, designated accession WW-1002, had a semi-prostrate growth habit and dark green foliage. It is similar in appearance to other naturally occurring gamagrass colonies found along creeks and protected lowland habitats in northwest Oklahoma and the Texas Panhandle. 
Propagules were transplanted into the field on a $91-\times 91-\mathrm{cm}$ centers at the U.S. Southern Great Plains Field Station, Woodward, Okla., in June 1975. The soil of the experimental area is a Carey silt loam (Thermic Typic Argiustolls). During 1976-77, irrigation water was applied as require to bring the total precipitation up to $7.5 \mathrm{~cm}$ per 10-day period. The plants were left undisturbed during the growing season and the accumulated standing forage was removed by burning in March 1976 and 1977. The presence or absence of charred plant material subsequently facilitated the separation of shoots which were initiated prior to 1977 from those initiated following the 1977 burn.

Shoots were classified according to the terminology of Stubbendieck and Burzlaff (1970). Young lateral shoots with the leaf of the first complete phytomer growing beyond the prophyllum and budscale leaf, but which had not yet produced a root, were classified as tillers. Shoots with at least one root, but without secondary shoots, were classified as single shoots; and shoots giving rise to secondary shoots were classified as compound shoots. Shoots with at least one partially elongated seed stalk internode were classified as reproductive shoots. These structural components of the shoot system are shown in Figure 1 .

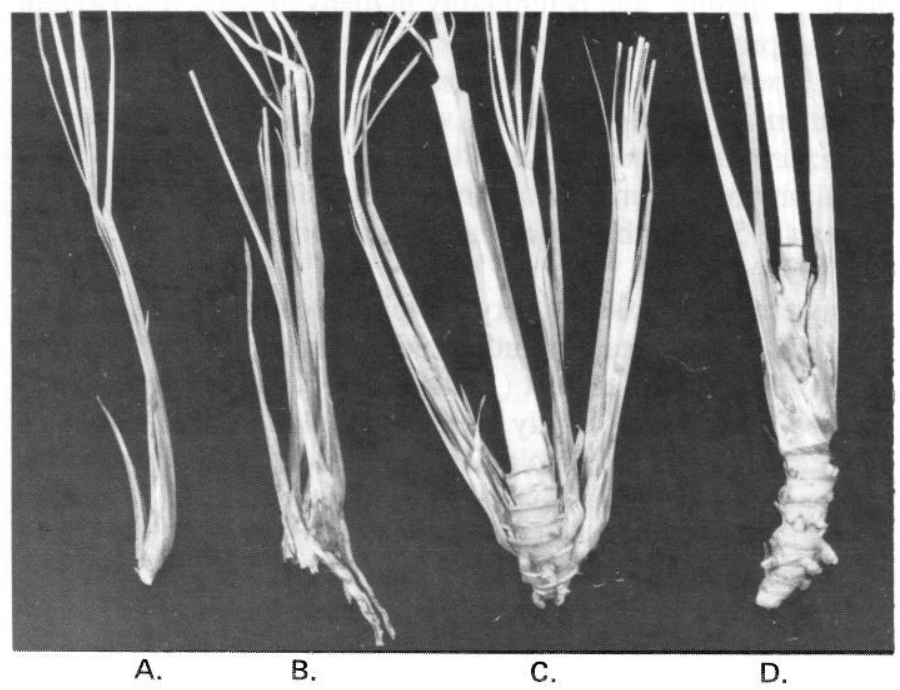

Fig. 1. Structural components of the shoot system of eastern gamagrass: (a) tiller; (b) single shoot; (c) compound shoot; (d) reproductive shoot.

The sequence of development was determined by examining crown components twice monthly from November 1976 through October 1977. The proportions of the various structural components are expressed herein as percentages of the number of total active structural units (TASU), or as percentage of the number of active structural units initiated before 1977 (ASU before 77). We considered active structural units to be the total number of active crown components present at the time of examination; dead shoots and spent proaxes that had terminated growth prior to 1977 were therefore excluded. The number of shoots classified ranged from 121 to 441 (Avg. 256 TASU) for each examination interval.

The number of roots developed by single shoots was recorded on each examination date from January through October 1977. These data are presented as a percentage of the total number of shoots that had developed given numbers of roots. The number of shoots examined varied from 30 to 138 (Avg. 74) on the different examination dates.

The number of mature phytomers developed on single shoots was also recorded on each examination date from January through October 1977. A useful characteristic was found which facilitated the determination of mature phytomer numbers. When a phytomer of accession WW-1002 had matured to the extent that its components (blade, sheath, and internode) are fully elongated, a dark band formed around the shoot at the junction of the internode and the sheath. By locating the lowermost internode on the shoot which is not fully elongated, and consequently without the accompanying dark band, a specific point in shoot development is determined. The phytomers below this point are considered to be "mature phytomers." The number of mature phytomers on a shoot was thus determined by counting the leaves (or internodes if leaves were missing) between the lowermost immature phytomer and the prophyllum and bud scale leaves or their leaf scars. The data are presented as the percentages of the total number of shoots that had developed given numbers of mature phytomers.

\section{Results and Discussion}

Crowns of eastern gamagrass consisted of tillers, single shoots, compound shoots, and reproductive shoots in various stages of development. These structural components were held together by a woody proaxis chain and underwent a series of changes in an orderly fashion.

\section{Tillers}

\section{Tillers Initiated before 1977}

Tillers made up 30 to $40 \%$ of the TASU during winter dormancy, November 1976 to February 1977, and 25 to $35 \%$ thereafter through May 5, 1977 (Fig. 2A). The percentage of tillers increased to $48 \%$ by May 20 apparently as an indirect result of the decrease in TASU from mortality of compound shoots. The percentage of tillers declined steadily between May 20 and August 8, and by August 23 all tillers had produced roots and were thus classified as single shoots. Shoots that remained in the tiller stage until August 1977 were at least 10 months of age.

\section{Tillers Initiated during 1977}

Lateral buds first developed to the tiller stage in late May or early June (Fig. 2A). Tiller production continued until October 13, resulting in an age differential of 4 months in tillers initiated in 1977 . About $60 \%$ of the shoots initiated in 1977 , primarily those initiated late, did not produce roots during the 1977 growing season, but remained in the tiller stage, representing 25 to $30 \%$ of the TASU during September and October.

\section{Single Shoot Development}

\section{Single Shoots Initiated before 1977}

Each mature phytomer usually produced no more than one root which developed opposite the lateral bud on the ventral surface of the shoot. Production of two roots by the same phytomer and production of roots on the dorsal surface of single shoots were rare. Root initiation usually took place after the phytomer was mature, but occasionally a root grew from the most basal, immature phytomer. Single shoots occasionally had as many as 13 roots, but most had 10 or less.

Single shoots made up 33 to $45 \%$ (Avg. 41\%) of the TASU between November 1976 and February 1977 (Fig. 2B). In January and February 1977, 69\% of the shoots had one or two roots; $57 \%$ of such shoots had no more than four mature phytomers (Table 1). In the same two months less than $10 \%$ of the shoots had five or more roots, all of which had five or more mature phytomers developed, indicating they had probably been initiated during 1975.

In March and April 1977 the percentage of single shoots was slightly higher (Avg. 48\%) than during the preceding months (Fig. 2B). The percentage of shoots with one or two roots remained about the same, but the percentage with only two to four mature phytomers had increased to $75 \%$ (Table 1), indicating that the rate at which tillers were rooting had increased since the previous examination period.

During May the percentage of single shoots decreased to $26 \%$ (Fig. 2B), apparently as a direct result of their transformation to reproductive shoots. The percentage of single shoots increased 


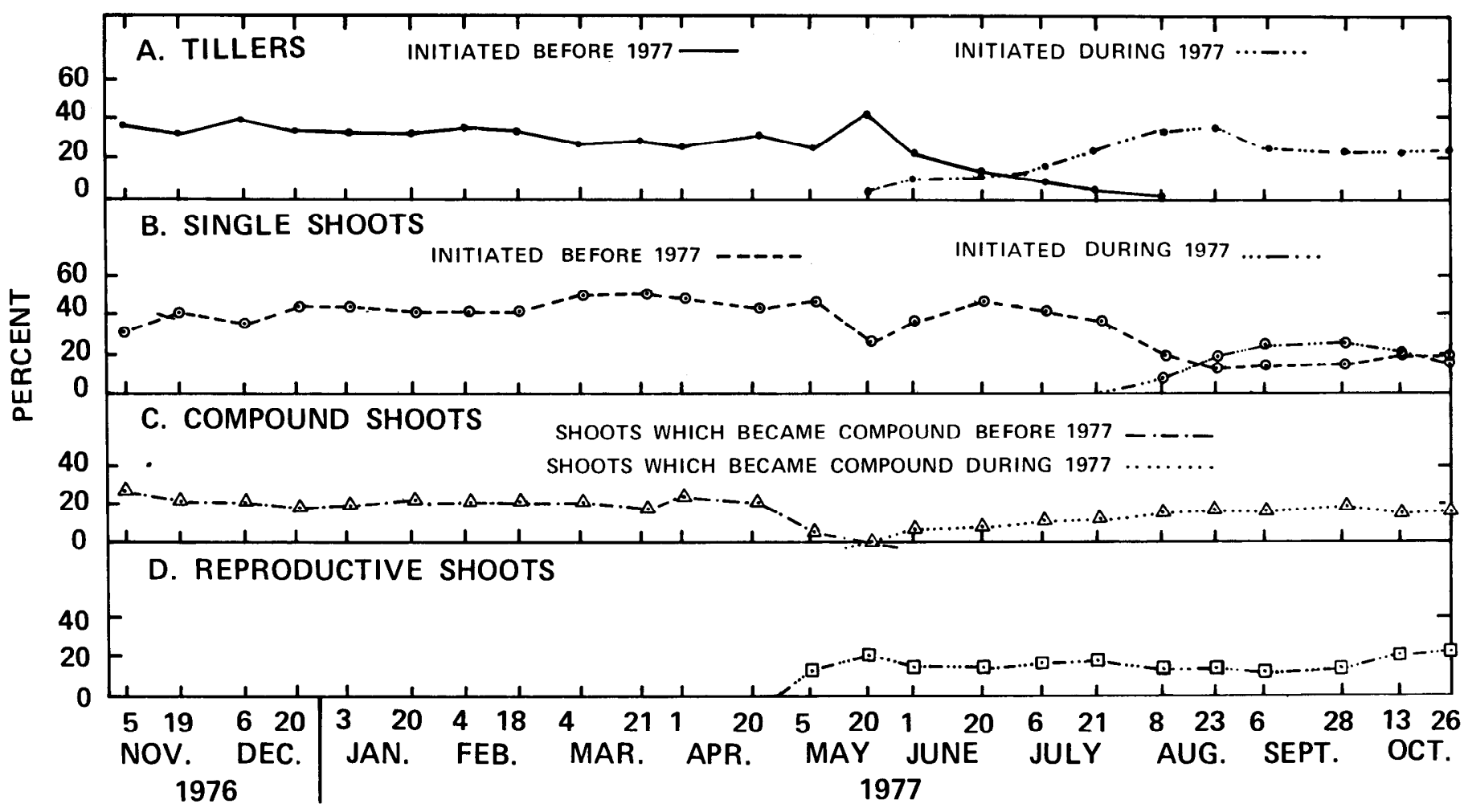

Fig. 2. Percentage composition of total active structural units in shoot systems of eastern gamagrass from November 1976 through October 1977; (a)

during June, suggesting that the rate at which tillers were rooting exceeded the rate at which reproductive and compound shoots were developing from single shoots.

In early summer, from June 20 to July 21,1977 , the percentage of single shoots remained nearly constant as development of new single shoots was about equal to the transformation of older single shoots. For ASU before 1977, the rate of tiller decline was about equal to the rates of increase in percentages of reproductive and compound shoots (Fig. 3). The percentage of single shoots decreased during August and leveled off in September to comprise 30 to $35 \%$ of the ASU before 1977 (Fig. 3) and about 20\% of the TASU (Fig. 2B).

The rate at which mature phytomers were developing increased more rapidly than the rate at which tillers were rooting during July through October, as indicated by the increase in the percentage with only one to four roots (Table 1). These changes parallel the decline and depletion of the tiller source (Fig. 3). All single shoots initiated before 1977 had developed at least eight and no more than 20 mature phytomers by the date of first killing frost (October 13, 1977).

Single Shoots Initiated in 1977

The development of single shoots began with the rooting of 1977-initiated tillers between July 21 and August 8 and continued into September (Fig. 2B). The single shoots that developed from these tillers produced no more than six mature phytomers and five roots during the 1977 growing season. More than $75 \%$ of the single shoots produced only one or two roots. From August 8 through September 6, less than 15\% of the shoots had produced three or more mature phytomers; whereas from September 28 through October 26, about $90 \%$ had produced three or more (Table 2). Occasionally, roots werc observed on the most basal immature phytomers.

\section{Development of Compound Shoots}

Compound shoots made up from 18 to $28 \%$ (Avg. 22\%) of the tillers; (b) single shoots; (c) compound shoots; (d) reproductive shoots.

TASU from November 5 to April 20, 1977 (Fig. 2C). The percentage of compound shoots had decreased to $7 \%$ by May 5 and no compound shoots were observed on May 20. This

Tahle 1. Percentage of single shoots' of eastern gamagrass that developed various numbers of roots and mature phytomers in consecutive 2 -month intervals from January to October 1977.

\begin{tabular}{|c|c|c|c|c|c|c|c|}
\hline \multirow{2}{*}{$\begin{array}{l}\text { Range in number } \\
\text { of roots }\end{array}$} & \multicolumn{7}{|c|}{ Range in number of mature phytomers } \\
\hline & $2-4$ & $5-7$ & $8-10$ & $11-13$ & $14-16$ & $17-20$ & All (2 to 20$)$ \\
\hline \multicolumn{8}{|l|}{ Jan.-Feb. } \\
\hline $1-2$ & 57 & 42 & 0 & 0 & 0 & 0 & 69 \\
\hline $3-4$ & 13 & 79 & 3 & 5 & 0 & 0 & 22 \\
\hline $5-6$ & 0 & 86 & 7 & 7 & 0 & 0 & 5 \\
\hline $7-10$ & 0 & 14 & 14 & 43 & 29 & 0 & 4 \\
\hline \multicolumn{8}{|l|}{ March-April } \\
\hline $1-2$ & 75 & 23 & 1 & 1 & 0 & 0 & 68 \\
\hline $3-4$ & 24 & 62 & 12 & 2 & 0 & 0 & 22 \\
\hline $5-6$ & 0 & 55 & 22 & 22 & 0 & 1 & 6 \\
\hline $7-10$ & 0 & 0 & 14 & 36 & 43 & 7 & 4 \\
\hline \multicolumn{8}{|l|}{ May-June } \\
\hline $1-2$ & 33 & 53 & 15 & 0 & 0 & 0 & 54 \\
\hline $3-4$ & 12 & 59 & 22 & 4 & 1 & 1 & 29 \\
\hline $5-6$ & 0 & 45 & 36 & 7 & 12 & 0 & 13 \\
\hline $7-10$ & 0 & 6 & 41 & 12 & 23 & 18 & 4 \\
\hline \multicolumn{8}{|l|}{ July-Aug. } \\
\hline $1-2$ & 29 & 29 & 29 & 14 & 0 & 0 & 15 \\
\hline $3-4$ & 7 & 26 & 45 & 20 & 3 & 0 & 34 \\
\hline $5-6$ & 2 & 15 & 46 & 31 & 3 & 2 & 27 \\
\hline $7-10$ & 0 & 1 & 34 & 45 & 10 & 10 & 25 \\
\hline \multicolumn{8}{|l|}{ Sept.-Oct. } \\
\hline $1-2$ & 0 & 6 & 19 & 31 & 38 & 6 & 9 \\
\hline $3-4$ & 0 & 4 & 12 & 31 & 42 & 12 & 16 \\
\hline $5-6$ & 0 & 10 & 12 & 30 & 38 & 10 & 25 \\
\hline $7-10$ & 0 & 2 & 4 & 28 & 51 & 15 & 50 \\
\hline
\end{tabular}

Initiated before the 1977 growing season. The number examined varied from 135 to 259 (Av. 208) in the different examination periods. 
Anderson, E. 1944. Cytological observations on Tripsacum dactyloides. Ann. Missouri Bot. Garden. 31:317-323.

Arber, A. 1934. The Gramineae: a study of cereal, bamboo, and grass. Cambridge Univ. Press. 480 p.

Cutler, H.C., and E. Anderson. 1941. Preliminary survey of the genus Tripsacum. Ann. Missouri Bot. Garden. 28:249-269.

Evans, M.W. 1927. The life history of timothy. U.S. Dep. Agr. Bull. 1450. $56 \mathrm{p}$.

Evans, M.W. 1958. Growth and development in certain economic grasses. Ohio Agr. Exp. Sta., Agron. Serv. 147. 123 p.

Evans, M.W., and F.O. Grover. 1940. Developmental morphology of the growing point of the shoot and inflorescences in grasses. J. Agr. Res. 61:481520 .

Gray, A. 1879. Structural Botany. American Book Co., New York 442 p.

Hitchcock, A.S. 1951. Manual of the Grasses of the U.S. 2nd Ed., rev. U.S. Dep. Agr. Misc. Pub. 2001051 p. Revised by A. Chase.

Hitchcock, A.S., and G.L. Clothier. 1899. Native agricultural grasses of Kansas. Kansas State Agr. Coll. Bull. 87 p. 5-6.

Holm, T. 1929. The application of the term "rhizome." Rhodora. 31:6-17.

Hyder, D.N. 1974. Morphogenesis and management of perennial grasses in the United States. U.S. Dep. Agr. Misc. Bull. 1271 p. 89-98.

Killebrew, J.B. 1878. The grasses of Tennessee including cereal and forage plants. The Amer. Co., Nashville. p. 107-108.

Magoffin, J. 1843. Culture of gamagrass. The Southern Cultivator 1: 103-104.

Newell, C.A., and J.M.J. deWet. 1974. Morphological and cytological variability in Tripsacum dactyloides. Amer. J. Bot. 61:652-664.
Polk, D.B., and W.L. Adcock. 1964. Eastern gamagrass. Cattleman 50:8284.

Rechenthin, C.A. 1951. Range grasses in the Southwest; Eastern gamagrass, Texas cupgrass, Pan American balsamscale and smooth cordgrass. Cattleman 38:110-112.

Rechenthin, C.A. 1956. Elementary morphology of grass growth and how it affects utilization. J. Range Manage. 9:167-170.

Sharman, B.C. 1945. I eaf and bud initiation in the Gramineae. Bot. Gaz. 106:269-289.

Sims, P.L., R.K. Lang' at, and D.N. Hyder. 1973. Developmental morphology of blue grama and sand bluestem. J. Range Manage. 26:340-344.

Strasbuger, E., F. Noll, H. Schenck, and A.F.W. Schimper. 1903. A Textbook of Botany; translated by H.C. Porter. The Macmillan Co., New York. $671 \mathrm{p}$.

Stubbendieck, J., and D.F. Burzlaff. 1970. Effects of temperature and day length on axillary bud and tiller development in blue grama. J. Range Manage. 23:63-66.

Stubbendieck, J., and D.F. Burzlaff. 1971. Nature of phytomer growth in blue grama. J. Range Manage. 24:154-156.

Weatherwax, P. 1954. Indian corn in Old America. The Macmillan Co., New York. 245 p.

Wilcox, E.V., and C.B. Smith. 1905. Farmers cyclopedia of agriculture. Orange Judd Co., N.Y. 619 p.

Wilkes, H.G. 1972. Maize and its wild relatives. Science 177:1071-1077. Youngner, V.B. 1969. Physiology of growth and development. Turfgrass Sci. Agron. Service 14 p. 187-216. 